\title{
Effects of Helicobacter pylori vacuolating cytotoxin on primary cultures of human gastric epithelial
} cells

\author{
D T Smoot, J H Resau, M H Earlington, M Simpson, T L Cover
}

\begin{abstract}
Background-Many Helicobacter pylori strains produce a cytotoxin that induces cytoplasmic vacuolation in various types of eukaryotic cells. In contrast with the marked cell vacuolation that occurs in vitro in response to this cytotoxin, comparatively little epithelial vacuolation has been observed in the gastric mucosa of $\boldsymbol{H}$ pylori infected persons.
\end{abstract}

Aims-Experiments were performed to determine the susceptibility of human gastric epithelial cells in vitro to $H$ pylori vacuolating cytotoxin activity.

Methods-Human gastric epithelial cells, harvested from upper gastrointestinal endoscopic biopsy specimens, were incubated overnight with broth culture supernatants from either a wild type cytotoxin producing (tox $\left.{ }^{+}\right) H$ pylori strain or an isogenic mutant strain that lacks cytotoxin activity.

Results-Prominent cytoplasmic vacuolation occurred in response to tox ${ }^{+}$supernatant, but not supernatant from the isogenic mutant strain. Primary human gastric epithelial cells were significantly more sensitive to $H$ pylori vacuolating cytotoxin activity than were either HeLa or AGS cells. Exposure of human gastric epithelial cells to high concentrations of tox $^{+}$supernatant for $\mathbf{4 8}$ hours caused lethal cell injury.

Conclusions-These studies indicate that primary human gastric epithelial cells are highly sensitive to $H$ pylori vacuolating cytotoxin activity.

(Gut 1996; 39: 795-799)

Keywords: $H$ pylori, vacuolating cytotoxin, human gastric cell culture.

Helicobacter pylori is a Gram negative microaerophilic bacterium that colonises gastric epithelium and mucus in humans. Infection with this bacterium consistently causes chronic superficial gastritis, which is characterised by infiltration of the mucosa with acute and chronic inflammatory cells. ${ }^{1} H$ pylori is an important aetiological factor in the development of peptic ulcers, and infection with this organism is a significant risk factor for development of gastric cancer. ${ }^{2-4}$ Successful treatment of $H$ pylori infection with antibiotics not only heals peptic ulcers, but also greatly reduces ulcer recurrence rates. ${ }^{56}$
One potential virulence factor of $H$ pylori is a cytotoxin that induces vacuolation in eukaryotic cells. ${ }^{7}$ Approximately one half of all $H$ pylori isolates produce detectable vacuolating cytotoxin activity in vitro. Cytotoxin neutralising antibodies are present in sera from $H$ pylori infected persons, which indicates that the cytotoxin is produced in vivo. ${ }^{8}$ In addition, the prevalence of infection with cytotoxin producing $H$ pylori strains is higher among infected persons with peptic ulcers than among infected persons with gastritis alone. ${ }^{9-11}$ The vacuolating cytotoxin has been purified from $H$ pylori, and migrates as a $\sim 90 \mathrm{kDa}$ protein under denaturing and reducing conditions. ${ }^{12}$ Insertional mutagenesis of the gene encoding the cytotoxin (vacA) abolishes cytotoxin production. ${ }^{13-15}$ The $H$ pylori cytotoxin induces marked vacuolation in vitro in essentially $100 \%$ of exposed transformed epithelial cells. Although gastric epithelial cell vacuolation has been reported in $H$ pylori infected patients, ${ }^{16} 17$ this morphology has not been a prominent finding in gastric biopsy specimens. One possible explanation for the paucity of epithelial vacuolation in vivo is that gastric epithelial cells may be comparatively resistant to cytotoxin activity. The present studies were designed to determine the sensitivity of cultured primary human gastric epithelial cells to the cytotoxic effects of $H$ pylori vacuolating cytotoxin.

\section{Methods}

Bacterial strains and growth conditions $H$ pylori 60190 (ATCC 49503 ) is a wild type tox $^{+}$strain, and $H$ pylori $60190-\mathrm{v} 1$ is an isogenic mutant strain in which the vacA gene has been disrupted by insertional mutagenesis. ${ }^{13}$ Each strain was cultured in Brucella broth containing $5 \%$ fetal bovine serum (BB-FBS) for 48 hours, and after centrifugation of the cultures, supernatants were concentrated 40 -fold by ultrafiltration. ${ }^{18}$

Culture of primary gastric epithelial cells

Primary human gastric epithelial cells were isolated from gastric biopsy specimens of patients undergoing upper gastrointestinal endoscopy at Howard University Hospital as previously described..$^{19}$ Gastric biopsy samples were taken only from patients with macroscopically normal stomach mucosa. Only gastric cells obtained from patients without evidence of $H$ pylori on histological evaluation 
were used in these experiments. After enzymatic isolation, gastric epithelial cells were plated onto Labtek chamber slides (Nunc Inc, Naperville, IL) and cultured in Ham's F12 culture medium (Life Technologies, Grand Island, $\mathrm{NY}$ ) at $\mathrm{pH} 7 \cdot 4$, supplemented with $10 \%$ fetal bovine serum (Life Technologies), amphotericin B $(0.25 \mu \mathrm{g} / \mathrm{ml})$, penicillin G (100 units $/ \mathrm{ml})$, and streptomycin $(100 \mu \mathrm{g} / \mathrm{ml})$. Cells were cultured for three to five days before each experiment. The effects of $H$ pylori supernatant from the wild type tox ${ }^{+}$strain and the isogenic tox mutant strain on primary cultures on human gastric epithelial cells were compared in four different experiments. Each experiment used gastric cells from a different patient; however, individual experiments were performed using gastric cells from a single patient.

Quantitation of vacuolating cytotoxin activity Transformed cell lines (HeLa, AGS, HEp2, $\mathrm{CHO}, \mathrm{MA104}, \mathrm{MDCK}$, and Vero) were cultured in Eagle's medium or Ham's F12 medium ( $\mathrm{pH}=7 \cdot 4$ ) containing $10 \%$ fetal bovine serum, and seeded into 96 -well plates. Serial dilutions of $H$ pylori culture supernatants or partially purified vacuolating cytotoxin were added to primary cultures of human gastric epithelial cells or transformed cell lines, and incubated for 24 hours at $37^{\circ} \mathrm{C}$. Experiments comparing susceptibility of primary gastric cells with transformed cell lines were performed in duplicate and repeated twice. Cell vacuolation was quantitated by visual inspection by two persons blinded to the treatment conditions, using phase contrast microscopy. Alternatively, in some experiments, cell vacuolation was quantitated by neutral red uptake assay. ${ }^{20}$

\section{Lethal cytotoxicity experiments}

Cell viability was assessed by incubating cells in calcein AM and ethidium homodimer (Live/ Dead Assay, Molecular Probes, Eugene, OR). Live cells were distinguished by the presence of intracellular esterase activity, which converts the virtually non-fluorescent cell-permeant calcein AM to the intensely fluorescent calcein. The polyanionic calcein is retained within the cytoplasm of live cells, producing an intense uniform green fluorescence. Ethidium homodimer enters cells with damaged membranes and upon binding nucleic acids undergoes a 40-fold enhancement of fluorescence, thereby producing a bright red fluorescence within the nucleus of dead cells. The results are expressed as number of live cells/100 cells counted and represent the data from three separate experiments. Data were analysed for statistical significance using the Student's $t$ test.

\section{Results}

Effects of the vacuolating cytotoxin on primary gastric epithelial cells

To determine whether human gastric epithelial cells are susceptible to $H$ pylori vacuolating cytotoxin activity, primary cultures of human gastric cells were incubated overnight with concentrated supernatant from tox ${ }^{+} H$ pylori strain 60190 , its isogenic mutant $60190-\mathrm{v} 1$, or uninoculated concentrated BB-FBS. $H$ pylori supernatant from strain 60190 induced prominent vacuoles in the gastric epithelial cells (Fig 1A). In contrast, primary human gastric epithelial cells exposed overnight to culture medium containing either broth supernatant from the mutant $H$ pylori strain or uninoculated BB-FBS, did not develop intracellular vacuoles (Fig $1 B$ and $C$ ).

\section{Relative susceptibility to vacuolating cytotoxin activity}

Early studies by Leunk et al suggested that various transformed cell lines differed in susceptibility to cytotoxin activity. ${ }^{7}$ To investigate this phenomenon further, monolayers of seven different cell lines (including four cell lines tested by Leunk et al) were incubated with serial dilutions of the vacuolating cytotoxin from $H$ pylori 60190 , purified partially by hydrophobic interactive chromatography. ${ }^{12}$ After 24 hours, cell vacuolation was quantitated by neutral red uptake assay. ${ }^{20}$ As shown in Figure 2, each of the cell lines tested was susceptible to the effects of $H$ pylori cytotoxin, with HeLa, AGS, and Hep-2 cells demonstrated as most sensitive.

We then sought to determine the relative susceptibility of cultured human gastric epithelial cells to cytotoxin activity. Unlike transformed cell lines, normal human gastric epithelial cells in culture do not proliferate at a constant rate and may terminally differentiate over time, which makes standardisation difficult; therefore, for this experiment vacuolation was quantitated by visual inspection rather than using the neutral red assay. As shown in Figure 3, primary human gastric epithelial cells were significantly more susceptible to vacuolating cytotoxin activity than were AGS or HeLa cells.

\section{Lethal vacuolating cytotoxin induced cell injury}

Previous studies have suggested that the vacuolating cytotoxin induces reversible, non-lethal injury in transformed cell lines. ${ }^{21-23}$ Therefore, we sought to determine whether the vacuolating cytotoxin induced lethal cell injury in human gastric epithelial cells. Primary cultures of human gastric epithelial cells were incubated for 24 and 48 hours in tissue culture medium containing concentrated broth culture supernatants from $H$ pylori strain 60190 or strain 60190-v1, standardised according to protein concentration. Tox ${ }^{+}$supernatant caused significant lethal gastric epithelial cell injury after 48 hours of incubation (Fig 4). In contrast, supernatant from tox strain $60190-\mathrm{v} 1$ failed to induce significant lethal cell damage (Fig 4). With incubations longer than 48 hours, the proportion of dead cells increased substantially in control wells, and therefore, these time points could not be evaluated. 

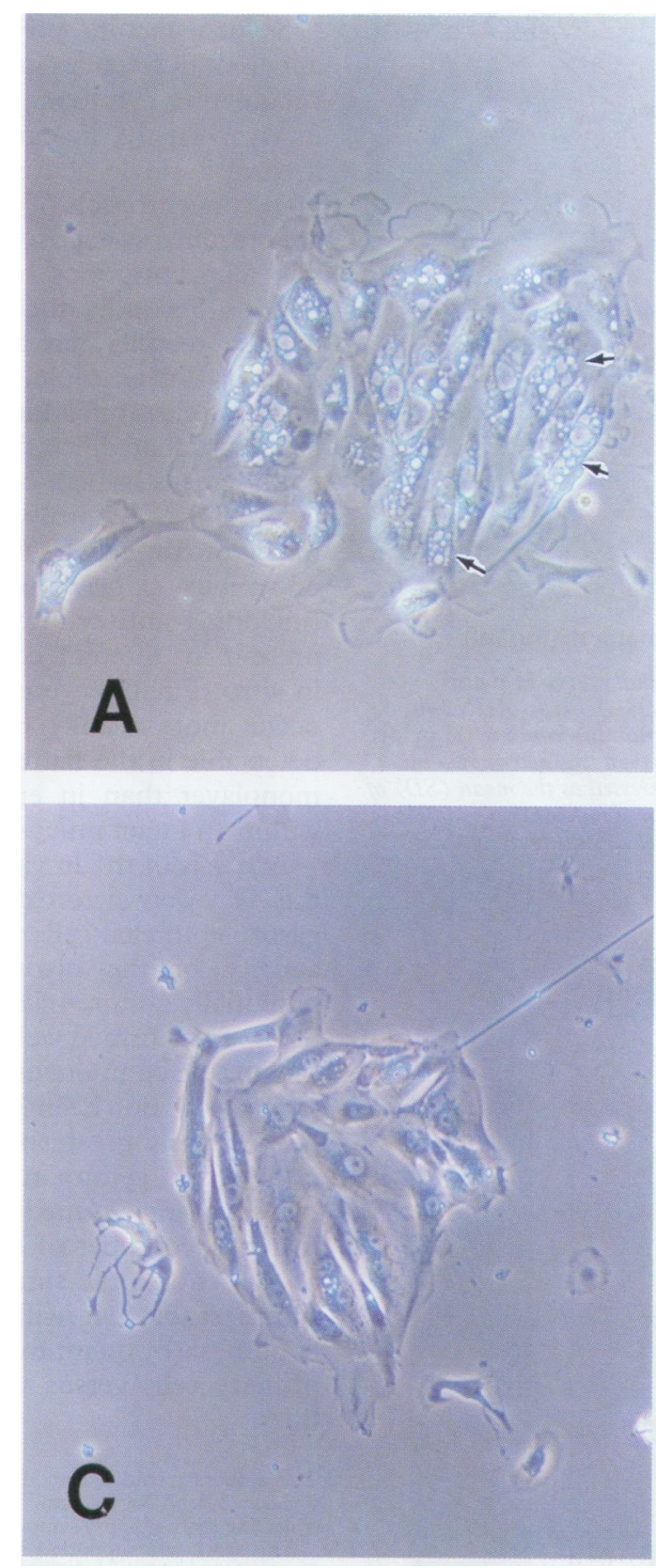

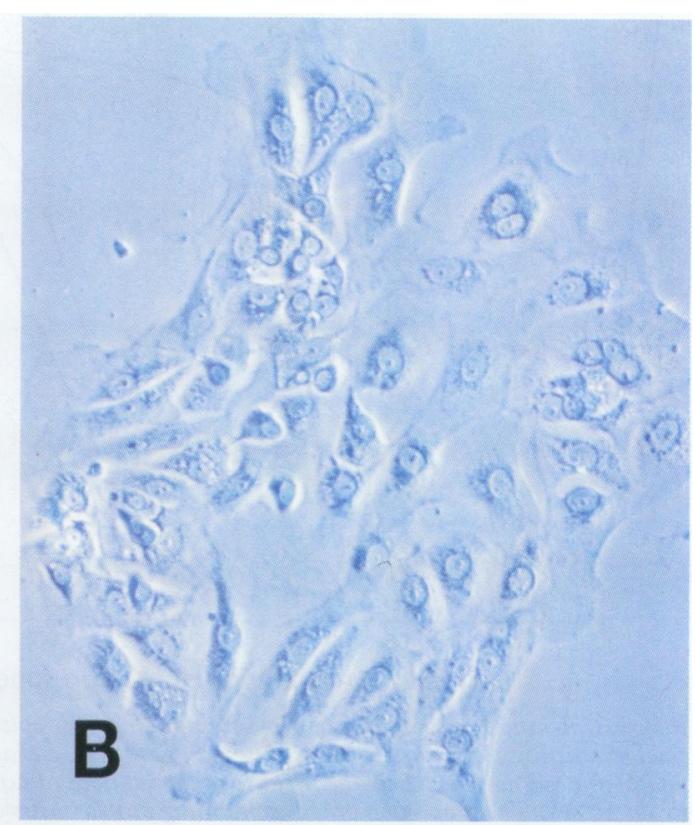

Figure 1: Effect of the vacuolating cytotoxin on primary gastric epithelial cells. Primary cultures of human gastric epithelial cells were incubated overnight with, $(A)$ culture medium containing both supernatant from tox ${ }^{+} \mathrm{H}$ pylori strain 60190 , (B) culture medium containing both supernatant from the isogenic $\mathrm{H}$ pylori vacA-mutant strain (60190-v1), or (C) cell culture medium alone. H pylori supernatant concentrations were adjusted and standardised to yield a final protein concentration of $2 \mathrm{mg} / \mathrm{ml}$ in tissue culture medium. Prominent vacuoles were detected only in cells incubated with supernatant from the tox ${ }^{+}$strain (see arrows in Fig 1A).

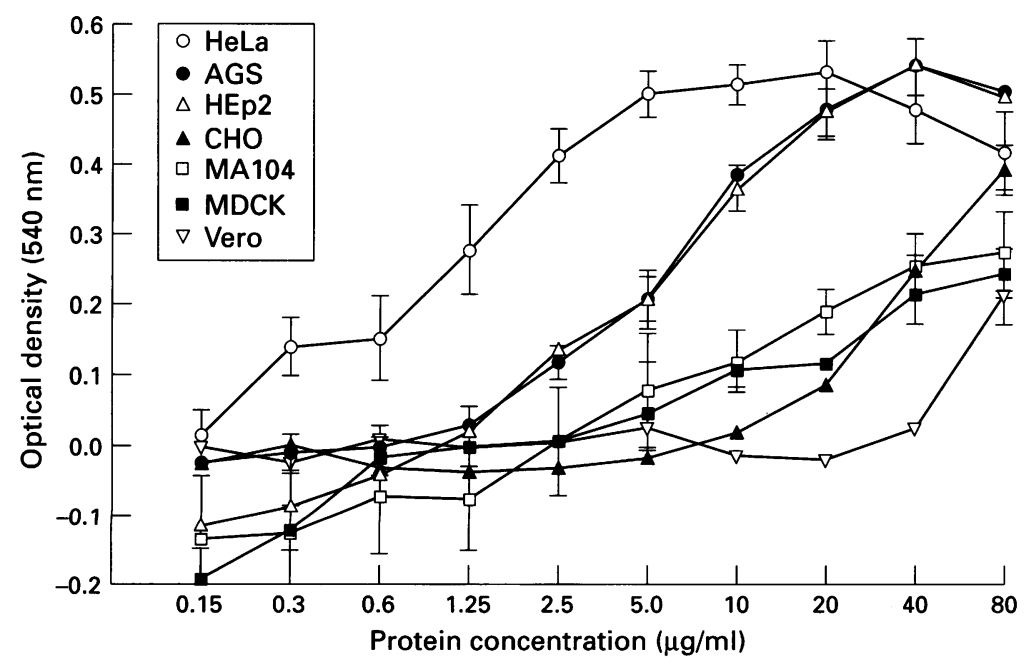

Figure 2: Vacuolation of multiple cell lines in response to $\mathrm{H}$ pylori cytotoxin. Seven different cell lines $\left(10^{4}\right.$ cells/well) were incubated overnight with serial dilutions of partially purified cytotoxin from tox ${ }^{+} \mathrm{H}$ pylori strain 60190 in culture media containing $10 \mathrm{mM}$ ammonium chloride. Vacuolation then was quantitated by neutral red uptake assay. ${ }^{20} \mathrm{HeL}$ a cells were most sensitive to cytotoxin activity, followed by $A G S$ and Hep-2 cells, which had almost identical responses.

\section{Discussion}

The results of this study show that human gastric epithelial cells are highly sensitive to the activity of the $H$ pylori vacuolating cytotoxin. In several previous studies, vacuolation of gastric epithelial cells has been demonstrated in gastric biopsy specimens from $H$ pylori infected persons. ${ }^{16}{ }^{17}$ However, epithelial cell vacuolation is not a prominent histological feature. Moreover, in one study that compared the gastric histology of patients infected with tox ${ }^{+}$ strains with that of patients infected with tox ${ }^{-}$ strains, no significant differences in levels of epithelial cell vacuolation were detectable. ${ }^{18}$

The activity of the $H$ pylori vacuolating cytotoxin on the gastric mucosa has also been assessed by administering purified cytotoxin directly into the stomachs of mice. This procedure results in localised regions of epithelial cell necrosis, loss of cytoplasm, and gastric ulceration in some cases. ${ }^{24}{ }^{25}$ Administration of bacterial sonicate from tox ${ }^{+}$strain 60190 induces similar epithelial lesions, whereas 


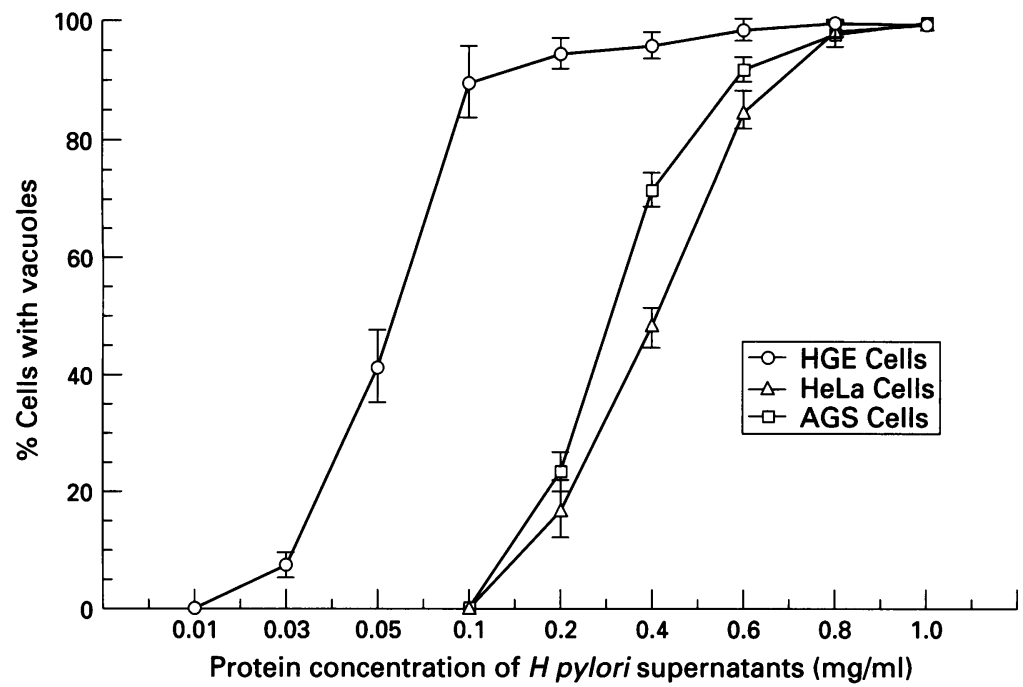

Figure 3: Relative susceptibility of primary human gastric epithelial cells to $\mathrm{H}$ pylori cytotoxin activity. Primary cultures of human gastric epithelial (HGE) cells, AGS cells, and $\mathrm{HeL}$ a cells were exposed overnight to serial dilutions of supernatant from tox ${ }^{+} \mathrm{H}$ pylori strain 60190. The proportion of cells containing visible vacuoles then was determined by visual inspection, using phase contrast microscopy. Data are expressed as the mean (SD) of triplicate experiments. Primary human gastric epithelial cells were significantly $(p<0.05)$ more susceptible to cytotoxin activity than were HeLa or AGS cells. Statistical analysis performed using Student's test for matched pairs.

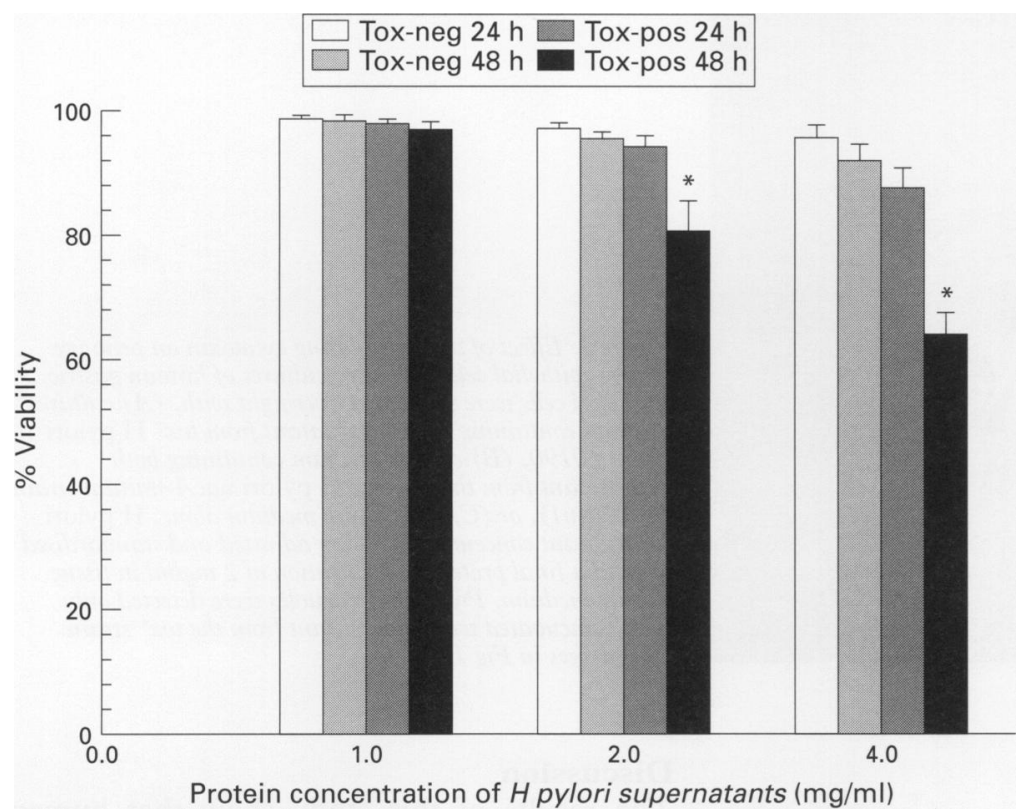

Figure 4: Effect of the $\mathrm{H}$ pylori cytotoxin on cell viability. Primary human gastric epithelial cells were incubated with supernatants from either tox ${ }^{+} \mathrm{H}$ pylori strain 60190 or an isogenic tox mutant strain (60190-v1), diluted in culture medium to final protein concentrations of 1,2 or $4 \mathrm{mg} / \mathrm{ml}$. After 24 and 48 hours of incubation, cell viability was assessed by staining with calcein $A M$ and ethidium homodimer. Tox ${ }^{+}$supernatant induced significant lethal cell injury after 48 hours of incubation. Statistical analysis was performed using the Student's test. ${ }^{\star} p<0.05$.

sonicate from the isogenic vacA-mutant strain 60190-v1 does not. ${ }^{26}$ Thus, in the mouse model, epithelial cell injury occurs in response to the cytotoxin. In several previous studies, it has been noted that cell vacuolation induced by the cytotoxin in vitro is reversible, either by removal of the cytotoxin or by addition of agents such as bafilomycin $\mathrm{A} 1 .^{21-23}$ The present study shows that exposure of cultured gastric epithelial cells to the cytotoxin for 48 hours results in lethal cell damage. Thus we hypothesise that longterm exposure of gastric epithelial cells to the cytotoxin in vivo may similarly result in cell death.
Several factors probably account for the apparent differences in response to the $H$ pylori vacuolating cytotoxin in vitro compared with in vivo. Firstly, in vitro experiments typically involve a single acute exposure of cells to a high concentration of cytotoxin, whereas cells are presumably exposed continuously in vivo to low concentrations of cytotoxin for long periods. Secondly, the mechanism of cytotoxin delivery to cells may be different in vitro and in vivo. For example, direct delivery of cytotoxin to cells from adherent bacteria may result in effects that differ from those produced by bathing cells in high concentrations of soluble cytotoxin. ${ }^{27} 28$ Thirdly, the response of cells to the cytotoxin may be modified by the presence of various $H$ pylori products or host factors (including anti-cytotoxin antibodies) that are present in different concentrations in vivo or in vitro. Finally, cytoplasmic vacuolation may occur more readily or may be more easily detectable in the flattened, adherent cells of a monolayer than in epithelial cells contained within an intact mucosal surface.

Analysis of the in vitro interactions between the $H$ pylori cytotoxin and normal human gastric epithelial cells provides insight into the activity of the cytotoxin in vivo, and is potentially a more relevant model than studies using transformed cell lines. At present, the membrane components to which the cytotoxin binds have not been characterised. However, the relatively greater susceptibility of primary cells to the cytotoxin compared with several types of transformed cells suggests that an increased number of cytotoxin receptors may be present on the surface of primary cells. In future studies, it will be useful to test this hypothesis by quantitating cytotoxin binding to primary cells versus various transformed cell lines.

The authors would like to thank Drs Sadye Curry, Hemant Joglekar, Joseph Nidiry, and Victor Scott for their assistance in collecting gastric biopsy samples.

This work was supported in part by Public Health Service This Service of the Department of Veterans Affairs, and Glaxo, Inc; and in part by the National Cancer Institute, DHHS, under and in part by the

1 Cover TL, Blaser MJ. Helicobacter pylori infection, a paradigm for chronic mucosal inflammation: pathogenesis and implications for eradication and prevention. Adv Intern Med 1996; 41: 85-117.

2 Correa P, Fox J, Fontham E, Ruiz B, Lin Y, Zavala D, et al. Helicobacter pylori and gastric carcinoma. Cancer 1990; 66: 2569-74.

3 Parsonnet J, Friedman GD, Vandersteen DP, Chang Y, Vogelman $\mathrm{JH}$, Orentreich $\mathrm{N}$, et al. Helicobacter pylori infection and the risk of gastric carcinoma. $N$ Engl $₹$ Med 1991; 325: 1127-31.

4 Hansson LE, Engstrand L, Nyren O, Evans DJ, Lingren A, Bergstrom $\mathbf{R}$, et al. Helicobacter pylori infection: independent risk indicator of gastric adenocarcinoma. Gastroenterology 1993; 105: 1098-103.

5 Forbes GM, Glaser ME, Cullen DJE, Warren JR, Christiansen KJ, Marshall BJ, et al. Duodenal ulcer reated with Helicobacter pylori eradication: seven-year follow-up. Lancet 1994; 343: 258-60.

6 Labenz J, Borsch G. Highly significant change of the clinical course of relapsing and complicated peptic ulcer disease after cure of Helicobacter pylori infection. Am 7 Gastroenterol 1994; 89: 1785-8.

7 Leunk RD, Johnson PT, David BC, Draft WG, Morgan DR. Cytotoxic activity in broth-culture filtrates of Campylobacter pylori. $₹$ Med Microbiol 1988; 26: 98-9.

8 Cover TL, Cao P, Murthy UK, Sipple MS, Blaser MJ. Serum neutralizing antibody response to the vacuolating cytotoxin of Helicobacter pylori. $\mathcal{F}$ Clin Invest 1992; 90: 913-8. 
9 Tee W, Lambert JR, Dwyer B. Cytotoxin production by Helicobacter pylori from patients with upper gastrointestinal tract diseases. $\mathcal{f}$ Clin Microbiol 1995; 33: 1203-5.

10 Figura N, Guglielmetti P, Rossolinia A, Barberi A, Cusi G, Musmanno RA, et al. Cytotoxin production by Campylobacter pylori strains isolated from patients with peptic ulcers and from patients with chronic gastritis only. f Clin Microbiol 1989; 27: 225-6.

11 Atherton JC, Cao P, Peek RM Jr., Tummuru MKR, Blaser MJ, Cover TL. Mosaicism in vacuolating cytotoxin Blaser MJ, Cover TL. Mosaicism in vacuolating cytotoxin
alleles of Helicobacter pylori: association of specific vacA types with cytotoxin production and peptic ulceration. f Biol Chem 1995; 270: 17771-7.

12 Cover TL, Blaser MJ. Purification and characterization of the vacuolating toxin from Helicobacter pylori. $\mathcal{F}$ Biol Chem 1992; 267: 10570-5.

13 Cover TL, Tummuru MKR, Cao P, Thompson SA, Blaser MJ. Divergence of genetic sequences for the vacuolating cytotoxin among Helicobacter pylori strains. F Biol Chem 1994; 269: 10566-73.

14 Schmitt W, Hass R. Genetic analysis of the Helicobacter pylori vacuolating cytotoxin: structural similarities with the IgA protease type of exported protein. Mol Microbiol the IgA protease typ

15 Phadnis SH, Ilver D, Janzon L, Normark S, Westblom TU. Pathological significance and molecular characterization of the vacuolating toxin gene of Helicobacter pylori. Infect Immun 1994; 62: 1557-65.

16 Tricottet V, Bruneval P, Vire O, Camilleri PJ. Campylobacter-like organisms and surface epithelium abnormalities in active, chronic gastritis in humans: an ultrastructural study. Ultrastruct Pathol 1986; 10: 113-22.

17 Hessey SJ, Spencer J, Wyatt JI, Sabala G, Rathbone BJ, Axon ATR, et al. Bacterial adhesion and disease activity in Helicobacter associated chronic gastritis. Gut 1990; 31: in Helico 8 .

18 Cover TL, Cao P, Lind CD, Tham KT, Blaser MJ. Correlation between vacuolating cytotoxin production by
Helicobacter pylori isolates in vitro and in vivo. Infect Immun 1993; 61: 5008-12.

19 Smoot DT, Resau JH, Naab T, Desbordes BC, Gilliam T, Bull-Henry $\mathrm{K}$, et al. Adherence of Helicobacter pylori to cultured human gastric epithelial cells. Infect Immun 1993; 61: 350-5.

20 Cover TL, Puryear W, Perez-Perez GI, Blaser MJ. Effect of urease on HeLa cell vacuolation induced by Helicobacter pylori cytotoxin. Infect Immun 1991; 59: 1264-70.

21 Cover TL, Reddy LY, Blaser MJ. Effects of ATPase inhibitors on the response of Hela cells to Helicobacter inhibitors on the response of Hela cells to Helicobacter 22 Papini E, Bugnoli $M$, DeBernard M, Figura N, Rappini E, Bugnoli M, DeBernard M, Figura N,
R, Montecucco C. Bafilomycin Al inhibits Helicobacter pylori-induced vacuolization of HeLa cells. Mol Microbiol 1993; 7: 323.

23 Cover TL, Halter SA, Blaser MJ. Characterization of HeLa cell vacuoles induced by Helicobacter pylori broth culture supernatant. Hum Pathol 1992; 23: 1004-10.

24 Telford $J$, Ghiara $P$, Dell'Orco $M$, Comanducci $M$, Burroni D, Bugnoli M, et al. Gene structure of the Helicobacter pylori cytotoxin and evidence of its key role in gastric disease. $\mathcal{F}$ Exp Med 1994; 179: 1653-8.

25 Marchetti M, Arico B, Burroni D, Figura N, Rappuol R, Ghiara P. Development of a mouse model of Helicobacter pylori infection that mimics human disease. Science 1995; 267: $1655-8$.

26 Ghiara P, Marchetti M, Blaser MJ, Tummuru MKR, Cover TL, Segal ED, et al. Role of the Helicobacter pylori virulence factors vacuolating cytotoxin, $\mathrm{CagA}$ and urease in a mouse model of disease. Infect Immun 1995; 63: 4154-60.

27 Zafriri D, Oron Y, Eisenstein BI, Ofek I. Growth advantage and enhanced toxicity of Escherichia coli adherent to tissue culture cells due to restricted diffusion of products secreted by the cells. $f$ Clin Invest 1987; 79: 1210-6.

28 Ofek I, Zafriri D, Goldhar J, Eisenstein BI. Inability of toxin inhibitors to neutralize enhanced toxicity caused by bacteria adherent to tissue culture cells. Infect Immun 1990; 58: $3737-42$. 